\title{
Chapter 2 \\ Grain Size Analysis and Maximum and Minimum Dry Density Testing of Ottawa F-65 Sand for LEAP-UCD-2017
}

\author{
Trevor J. Carey, Nicholas Stone, and Bruce L. Kutter
}

\begin{abstract}
Ottawa F-65 sand (supplied by US Silica, Ottawa, Illinois) was selected as the standard sand for LEAP-UCD-2017. Between December 2017 and February 2018, each LEAP research team sent $500 \mathrm{~g}$ samples of sand to UC Davis for grain size analysis and minimum and maximum dry density testing. The purpose of this testing was to confirm the consistency of the sand used at various test sites and to provide updated minimum and maximum density index values. The variation of measured properties among the different samples is similar to the variation measured during repeat testing of the same sample. Modified LEAP procedures to measure index densities are used to confirm consistency of the sands, and the results from these procedures are compared to results from ASTM procedures. The LEAP procedures give repeatable results with median index densities of $\rho_{\min }=1457 \mathrm{~kg} / \mathrm{m}^{3}$, $\rho_{\max }=1754 \mathrm{~kg} / \mathrm{m}^{3}$. Relative densities calculated with facility-specific index densities varied by less than $4 \%$, so we conclude that average index densities from all the sites may be used for analysis of the results. The LEAP procedures are easier to perform than the ASTM procedures and do not require specialized equipment; therefore, continued use of the LEAP procedure for frequent quality control purposes is recommended. However, the values from ASTM procedures are expected to be more consistent with values adopted in liquefaction literature in the past; therefore, we recommend using the median ASTM values for analysis of LEAP data. Index densities from ASTM procedures $\left(\rho_{\min }=1490.5 \mathrm{~kg} / \mathrm{m}^{3}, \rho_{\max }=1757.0 \mathrm{~kg} / \mathrm{m}^{3}\right)$ produce relative densities that are $4-10 \%$ smaller than the index densities from the LEAP procedures.
\end{abstract}

\subsection{Background and Introduction}

The standard sand selected for the LEAP-UCD-2017 exercise is Ottawa F-65, a clean, poorly graded, whole grain silica sand, with less than $0.5 \%$ fines by mass, supplied by US Silica, Ottawa, Illinois. The LEAP-GWU-2015 exercise also used Ottawa F-65 as the standard sand; therefore, material characterization and element

T. J. Carey $(\bowtie) \cdot$ N. Stone $\cdot$ B. L. Kutter

Department of Civil and Environmental Engineering, University of California, Davis, CA, USA

e-mail: tjcarey@ucdavis.edu

(C) The Author(s) 2020

B. Kutter et al. (eds.), Model Tests and Numerical Simulations of Liquefaction

and Lateral Spreading, https://doi.org/10.1007/978-3-030-22818-7_2 
test data from the LEAP-GWU-2015 exercise are applicable to the current LEAP exercise (Kutter et al. 2017; Vasko 2015). Recently, several researchers have performed additional element strength tests of Ottawa F-65 for different initial densities, confinements, and stress paths (Parra Bastidas 2016; Ziotopoulou et al. 2018).

The primary batch of Ottawa F-65 sand used in the LEAP-UCD-2017 exercise was delivered to UC Davis in March of 2013 as a 20-ton single-batch shipment of several pallets loaded with $25 \mathrm{~kg}$ bags. Being from the same shipment does not guarantee identical samples in each bag because US Silica does not mix the mined sand prior to shipment. Recognizing that the potential variability in soil properties among the $25 \mathrm{~kg}$ bags from a single batch may be smaller than the variability between different batches, the UC Davis team shipped sand to National Central University (Taiwan), Zhejiang University (China), Kyoto University, University of Cambridge, IFSTTAR, Ehime University, KAIST University, and K-Water Corporation. George Washington University (USA) ordered sand directly from US Silica in a single shipment; RPI ordered at least two shipments of sand from US Silica. Following centrifuge testing, between December 2017 and February 2018, all nine centrifuge facilities and George Washington University sent $500 \mathrm{~g}$ samples to UC Davis for grain size analysis and minimum and maximum index density testing using a modified LEAP procedure. However, the sand sent to Davis from RPI was from their most recent shipment of sand, while their LEAP experiments were conducted using a previous shipment of sand.

In August 2017, when instructions were released to the numerical simulation teams predicting the LEAP-UCD-2017 centrifuge experiments, Kutter et al. (2019) stated that based on tests conducted by many laboratories, the average minimum and maximum index dry densities for Ottawa F-65 were 1476 and $1765 \mathrm{~kg} / \mathrm{m}^{3}$, with standard deviations of 46 and $25 \mathrm{~kg} / \mathrm{m}^{3}$, respectively. Table 2.1 summarizes these and other index densities for Ottawa F-65 sand that the LEAP project has previously used. Updated recommendations for index densities are presented later.

Table 2.1 Previously used minimum and maximum densities for Ottawa F-65 sand

\begin{tabular}{l|l|l}
\hline Phase & $\begin{array}{l}\text { Minimum density } \\
\left(\mathrm{kg} / \mathrm{m}^{3}\right)\end{array}$ & $\begin{array}{l}\text { Maximum density } \\
\left(\mathrm{kg} / \mathrm{m}^{3}\right)\end{array}$ \\
\hline LEAP-GWU-2015 & 1519 & 1736 \\
\hline $\begin{array}{l}\text { LEAP-UCD-2017, } \\
\text { (Kutter et al. 2017) }\end{array}$ & 1475 & 1756 \\
\hline $\begin{array}{l}\text { LEAP-UCD-2017, August 2017, instructions to } \\
\text { numerical modelers }\end{array}$ & 1476 & 1765 \\
\hline
\end{tabular}




\subsection{Grain Size Analysis}

This section presents grain size analysis results of the $500 \mathrm{~g}$ samples that were sent from the experiment sites to UC Davis following the LEAP-UCD-2017 workshop. For each sample, a dry sieve analysis was performed, following ASTM C136 procedures. The US standard sieve numbers of 20,30, 40, 50, 60, 70, 100, and 200 were selected to describe the grain size distribution of Ottawa F-65 sand, with a specified mean grain size of $0.23 \mathrm{~mm}$, equal to the number 65 sieve opening. The grain size distribution (GSD) curves for the ten $500 \mathrm{~g}$ samples are shown in Fig. 2.1. Shown in Fig. 2.2 is the envelope of the gradation curves from Fig. 2.1. The specified gradation curve for Ottawa F-65 is shown with a dark black line in Fig. 2.1 and a dashed line in Fig. 2.2.

Fig. 2.1 Grain size distribution based on testing of $500 \mathrm{~g}$ samples sent from each experimental site and tested at Davis in spring 2018
Fig. 2.2 Envelope of the grain size distribution shown in Fig. 2.1
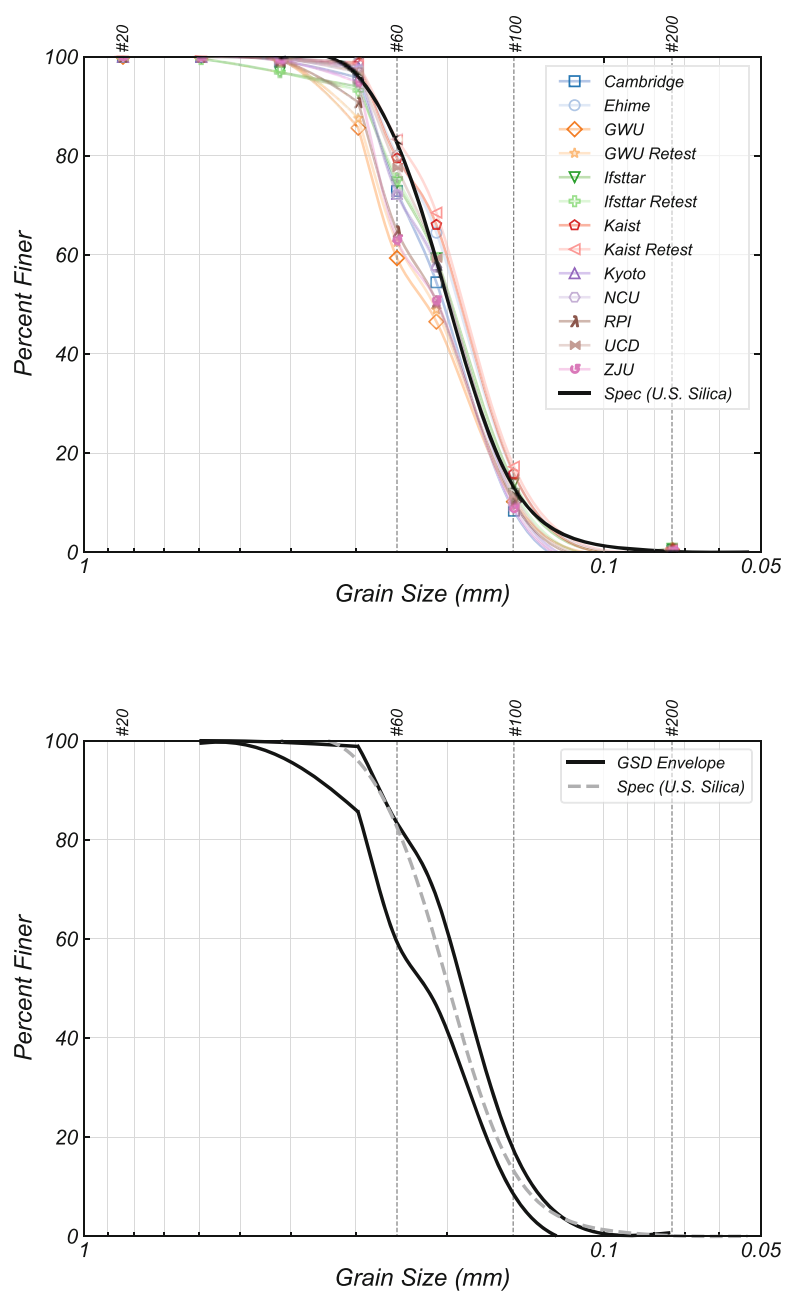
Table 2.2 Reported grain size distribution properties from sieve analyses performed at select experimental sites

\begin{tabular}{l|l|l|l|l}
\hline Facility (test) & $\mathrm{D}_{10}(\mathrm{~mm})$ & $\mathrm{D}_{30}(\mathrm{~mm})$ & $\mathrm{D}_{50}(\mathrm{~mm})$ & $\mathrm{D}_{60}(\mathrm{~mm})$ \\
\hline University of Cambridge (1) & 0.16 & 0.19 & 0.22 & 0.24 \\
\hline University of Cambridge (2) & 0.18 & 0.25 & 0.29 & 0.32 \\
\hline University of California Davis & 0.13 & 0.16 & 0.19 & 0.20 \\
\hline George Washington University & 0.14 & 0.17 & 0.21 & 0.23 \\
\hline KAIST University (1) & 0.13 & 0.17 & 0.20 & 0.21 \\
\hline KAIST University (2) & 0.13 & 0.17 & 0.20 & 0.21 \\
\hline KAIST University (supplement 1) & 0.12 & 0.17 & 0.20 & 0.21 \\
\hline KAIST University (supplement 2) & 0.14 & 0.18 & 0.20 & 0.22 \\
\hline RPI & 0.14 & 0.18 & 0.22 & - \\
\hline Zhejiang University (1) & 0.10 & 0.14 & 0.17 & 0.19 \\
\hline Zhejiang University (2) & 0.10 & 0.14 & 0.17 & 0.19 \\
\hline Zhejiang University (3) & 0.10 & 0.14 & 0.17 & 0.19 \\
\hline IFSTTAR (1) & 0.14 & 0.20 & 0.22 & 0.26 \\
\hline IFSTTAR (2) & 0.13 & 0.19 & 0.22 & 0.24 \\
\hline IFSTTAR (3) & 0.15 & 0.21 & 0.23 & 0.24 \\
\hline Average & 0.13 & 0.18 & 0.21 & 0.23 \\
\hline Standard deviation & 0.02 & 0.03 & 0.03 & 0.04 \\
\hline & & & &
\end{tabular}

Table 2.3 Grain size distribution properties (from Fig. 2.1) based on testing of $500 \mathrm{~g}$ samples sent from each test site to UC Davis for testing following the 2017 workshop

\begin{tabular}{l|l|l|l|l}
\hline Facility (test) & $\mathrm{D}_{10}(\mathrm{~mm})$ & $\mathrm{D}_{30}(\mathrm{~mm})$ & $\mathrm{D}_{50}(\mathrm{~mm})$ & $\mathrm{D}_{60}(\mathrm{~mm})$ \\
\hline University of Cambridge & 0.15 & 0.18 & 0.2 & 0.22 \\
\hline Ehime University & 0.14 & 0.17 & 0.19 & 0.2 \\
\hline George Washington University & 0.15 & 0.18 & 0.22 & 0.25 \\
\hline George Washington University (retest) & 0.15 & 0.18 & 0.21 & 0.24 \\
\hline IFSTTAR & 0.14 & 0.17 & 0.2 & 0.21 \\
\hline IFSTTAR (retest) & 0.14 & 0.17 & 0.2 & 0.21 \\
\hline KAIST University & 0.14 & 0.17 & 0.19 & 0.2 \\
\hline KAIST University (retest) & 0.14 & 0.16 & 0.19 & 0.2 \\
\hline Kyoto University & 0.15 & 0.17 & 0.2 & 0.21 \\
\hline National Central University & 0.15 & 0.17 & 0.2 & 0.21 \\
\hline RPI & 0.15 & 0.18 & 0.21 & 0.24 \\
\hline University of California Davis & 0.15 & 0.17 & 0.2 & 0.21 \\
\hline Zhejiang University & 0.15 & 0.18 & 0.21 & 0.24 \\
\hline Average & 0.15 & 0.17 & 0.20 & 0.22 \\
\hline Standard deviation & 0.01 & 0.01 & 0.01 & 0.02 \\
\hline
\end{tabular}

Tabulated in Table 2.3 are the $\mathrm{D}_{10}, \mathrm{D}_{30}, \mathrm{D}_{50}$, and $\mathrm{D}_{60}$ values for the curves shown in Fig. 2.1. Several research teams performed independent dry sieve testing and reported the $\mathrm{D}_{10}, \mathrm{D}_{30}, \mathrm{D}_{50}$, and $\mathrm{D}_{60}$ values from their analyses; the values obtained from their data templates are reported in Table 2.2. Also in Table 2.2 is the value reported for GWU by El Ghoraiby et al. (2017). 


\subsubsection{Discussion of Grain Size Analyses}

Figures 2.1 and 2.2 show the GSDs of the ten samples clustered around the specified distribution for Ottawa F-65. The GWU, RPI, and ZJU samples deviate from the specified distribution at grain sizes between 0.25 and $0.2 \mathrm{~mm}$. The GWU, RPI, and ZJU $D_{60}$ values reported in Table 2.3 are about $20 \%$ larger than the test average, but the $\mathrm{D}_{50}$ values are within about $5 \%$ of the average. The sand from GWU and RPI came from separate batches/shipments than the eight centrifuge facilities, and this small variability may be attributed to the different batches. ZJU used sand provided by UC Davis. The sand from the seven other facilities that received sand from UCD had almost identical gradations. Based upon all of the GSD analyses, especially those shown in Table 2.3 (tests done by one operator using the same set of sieves and sieve shaker), it appears that the sands used at various facilities are similar enough for practical purposes.

Assuming the permeability of the sand follows Hazen's empirical relationship, $\left(k=\mathrm{D}_{10}{ }^{2}\right)$, the uncertainty associated with the $\mathrm{D}_{10}$ values in Table 2.3 will propagate to the calculated permeability of the sand. The factor by which the permeability will change due to the uncertainty of $\mathrm{D}_{10}$ can be expressed as $\left.\mathrm{D}_{10}(\mathrm{Avg} \pm 1 \sigma)^{2} / \mathrm{D}_{10(\mathrm{Avg})}\right)^{2}$. For example, using the average $\mathrm{D}_{10}$ of $0.15 \mathrm{~mm}$ and standard deviation of $0.01 \mathrm{~mm}$ from Table 2.3 results in a change in permeability by a factor of $(0.16 / 0.15)^{2}=1.14$.

All sieve analyses were performed by the same operator, using the same equipment, eliminating uncertainty due to operator and equipment variation. Duplicate tests were conducted for the KAIST, IFSTTAR, and GWU samples to determine the repeatability of results and better understand the variability of the testing protocol. Table 2.4 summarizes the variation, in percent passing, of the three duplicate tests. The largest variation is observed on the No. 60 sieve, but the average range is still less than $3 \%$. From Table 2.3, the $\mathrm{D}_{30}, \mathrm{D}_{60}$, and $\mathrm{D}_{10}$ values of the retest data were all within $0.01 \mathrm{~mm}$ of each other. The variation detailed in Table 2.4 is consistent with the $0-4 \%$ average variation found by Tiedemann (1973), who using a different sand studied variability of duplicate grain size gradation testing.

Table 2.4 Summary of grain size gradation tests percent passing variations of duplicate tests

\begin{tabular}{l|l|l|l|l|l|l|l|l}
\hline & No. 20 & No. 30 & No. 40 & No. 50 & No. 60 & No. 70 & $\begin{array}{l}\text { No. } \\
100\end{array}$ & $\begin{array}{l}\text { No. } \\
200\end{array}$ \\
\hline Minimum range & $0.0 \%$ & $0.0 \%$ & $0.0 \%$ & $0.1 \%$ & $0.9 \%$ & $0.1 \%$ & $0.4 \%$ & $0.1 \%$ \\
\hline Maximum range & $0.0 \%$ & $0.0 \%$ & $0.0 \%$ & $1.9 \%$ & $3.9 \%$ & $2.4 \%$ & $1.4 \%$ & $0.2 \%$ \\
\hline Average range & $0.0 \%$ & $0.0 \%$ & $0.0 \%$ & $0.9 \%$ & $2.6 \%$ & $1.7 \%$ & $1.1 \%$ & $0.1 \%$ \\
\hline $\begin{array}{l}\text { Standard } \\
\text { deviation }\end{array}$ & 0.0 & 0.0 & 0.0 & 0.0 & 0.0 & 0.0 & 0.0 & 0.0 \\
\hline
\end{tabular}




\subsection{Minimum and Maximum Index Dry Density}

Minimum and maximum index dry density tests on the ten $500 \mathrm{~g}$ sand samples sent to Davis following the workshop are presented here. The detailed procedure to determine the index densities are described by Kutter et al. (2019), which uses a modified ASTM D4254 Method C and Modified Lade (1988) procedure, respectively. For the remainder of this publication, the Kutter et al. (2019) methods to measure density will be referred to as the LEAP method. The ASTM international standard was not ideal for quality control purposes at all facilities because it requires specialized equipment and it is more time-consuming. Furthermore, different standards are used in other countries. The LEAP method to measure index dry densities are relatively quick and reliable and were thought to be more practical for repeated quality control checks. However, several tests were also done using ASTM 4254 Method A (using a funnel device) and 4253 Method 1B (wet soil, vertically vibrating table) procedures by three different private laboratories and two university researchers, and these results are described later.

\subsubsection{LEAP Minimum Density Procedure}

Initially, $500 \mathrm{~g}$ of sand is placed in a $1000 \mathrm{ml}$ glass graduated cylinder. With the top of the cylinder sealed, the sample is turned upside down, then steadily rotated back upright at a constant rate, taking approximately 30-60 s to reach vertical. The volume of sand is then measured using the gradations on the graduated cylinder. The mass of the sand was measured, and the density calculated. For each sample, the test was repeated three times with the same sample of sand. This procedure is similar to the ASTM 4254 Method C procedure except the size of the graduated cylinder is reduced from 2000 to $1000 \mathrm{ml}$, which is considered to be large enough for the fine sand used in the LEAP exercise.

\subsubsection{LEAP Maximum Density Procedure}

Maximum density is found by adding ten $50 \mathrm{~g}$ increments of sand to a $1000 \mathrm{ml}$ plastic graduated cylinder. After each increment of sand is added, the side of the cylinder is tapped two times with the plastic handle of a screwdriver at the level of the sand and rotated 90 degrees and tapped again, for a total of eight taps per $50 \mathrm{~g}$ increment of sand. The striking distance the screwdriver is swung prior to contacting the plastic cylinder is 250 to $300 \mathrm{~mm}$, with a target distance of $275 \mathrm{~mm}$ for this study. The mass of the screwdriver is approximately $140 \mathrm{~g}$. Following the eight taps for the final $50 \mathrm{~g}$ increment of sand, six additional lighter taps are made on each 90-degree face (24 total taps). To level the top surface for purposes of accurate reading of the 
cylinder gradation, five to ten very light taps are made while the cylinder is tilted. The volume is read from the graduated cylinder, and the mass of the soil is measured.

\subsubsection{Results of Index Dry Density Testing}

The index density testing was performed and repeated by three operators, following the LEAP procedures. All three individuals used the same graduated cylinders and screwdrivers, minimizing systematic variability from different equipment. Graduated cylinder volume measurements were calibrated by filling the cylinder with a measured mass of water, and the necessary correction (about 1\%) was applied to all volume measurements. Prior to testing, the samples were set out in grounded metal trays for 1 week to equilibrate to ambient moisture and limit differences of static electrical charge. To minimize the effect of differential relative humidity on results, much of the testing occurred on the same day, in the same laboratory with nearconstant relative humidity. Following each density test, the sample of sand was placed back in the grounded metal tray to dissipate electrostatic charge that may have accumulated during the movement of the soil. A humidity sensor was also buried in the sand to check if the humidity in the soil pore space was similar to the ambient room humidity. The humidity measurements varied from 32 to $48 \%$.

Table 2.5 summarizes the results from the three operators of this study and provides the site-specific average values. The minimum dry density reported for each operator is the average of three trials of tilting the cylinder and recording the volume and mass. Trial-to-trial standard deviations of these three trials for each individual operator, 1,2 , and 3, are indicated by $\mathrm{STD}_{1}, \mathrm{STD}_{2}$, and $\mathrm{STD}_{3} . \mathrm{STD}_{\mathrm{O}}$ is the operator-to-operator standard deviation, calculated from the operator average values $\left(\mathrm{Avg}_{1}, \mathrm{Avg}_{2}, \mathrm{Avg}_{3}\right)$ for each sample. For example, for $\mathrm{CU}, 14.4 \mathrm{~kg} / \mathrm{m}^{3}$ is the standard deviation of 1465,1448 , and $1436 \mathrm{~kg} / \mathrm{m}^{3}$; the minimum density sitespecific average (Min $A v g_{s s}$ ) from all operators $\left(1450 \mathrm{~kg} / \mathrm{m}^{3}\right.$ for CU) is the average of averages from each operator 1465,1448 , and $1436 \mathrm{~kg} / \mathrm{m}^{3}$. STD shown in the bottom row is the standard deviations of all of the $\mathrm{Avg}_{\mathrm{Ss}}$ values. Since $\operatorname{STD}_{\mathrm{S}}=7.7 \mathrm{~kg} / \mathrm{m}^{3}$ is less than the average $\operatorname{STD}_{\mathrm{O}}=12.2 \mathrm{~kg} / \mathrm{m}^{3}$, it seems that the site-to-site variability of minimum density is smaller than the operator-to-operator variability of the LEAP method.

While three trials per operator were done for minimum density tests, one trial of the maximum density test was done by each of three operators. Therefore, standard deviation of the maximum densities (STD Max) includes trial-to-trial and operatorto-operator variability.

Illustrated in Fig. 2.3a, b are the facility-specific averages from Table 2.5. Figure 2.3b shows the entire range of data, whereas Fig. 2.3a uses a split vertical scale to exaggerate the differences. The vertical lines in Fig. 2.3a, b represent plus and minus one standard deviation $\left(\mathrm{STD}_{\mathrm{O}}\right)$. The mean minimum and maximum index densities determined with the LEAP procedures are 1451 and $1753 \mathrm{~kg} / \mathrm{m}^{3}$, respectively. 


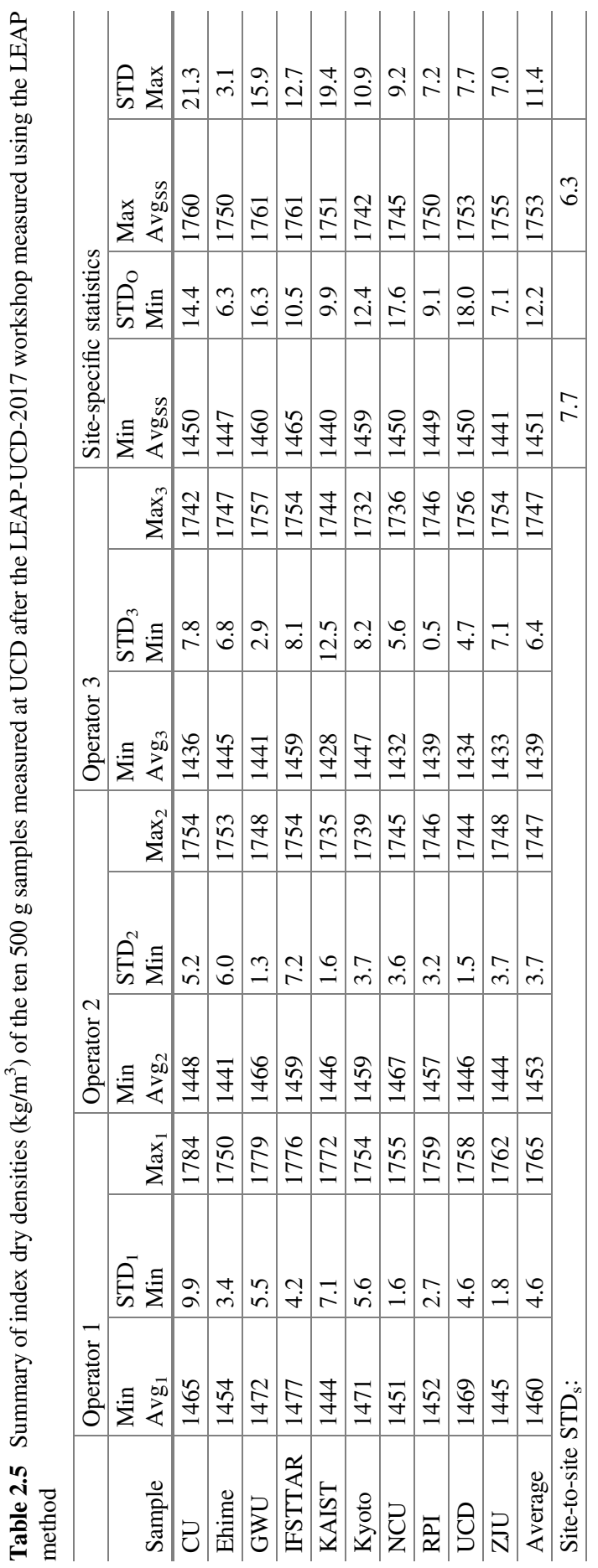



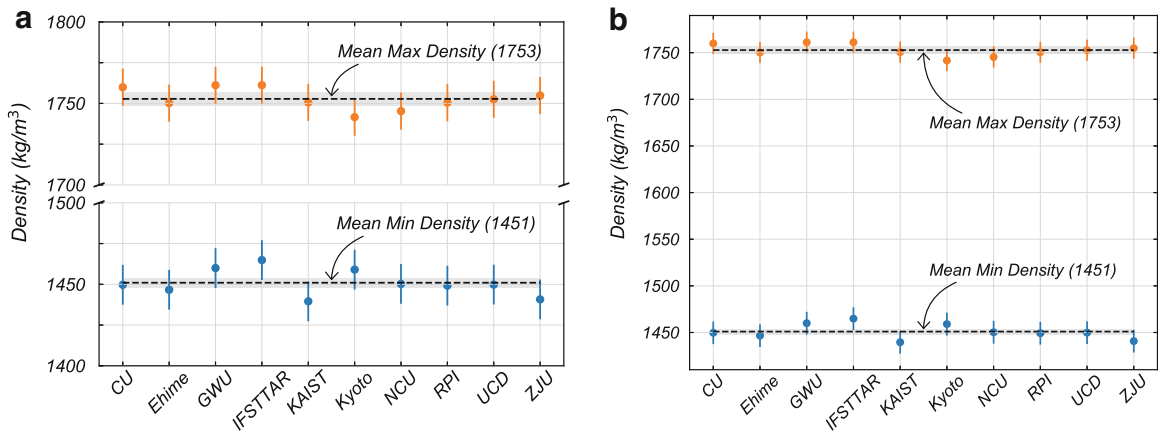

Fig. 2.3 Index dry density values of the sand from each test facility, with the mean value and $95 \%$ confidence of the mean (gray region) shown with, (a) split scale and (b) linear scale. The error bars in both figures represent the average operator-to-operator standard deviation, $\mathrm{STD}_{\mathrm{O}}=12.2 \mathrm{~kg} /$ $\mathrm{m}^{3}$ of the minimum densities and the average $\mathrm{STD}=11.4 \mathrm{~kg} / \mathrm{m}^{3}$ of the maximum densities

\subsubsection{Discussion of Minimum Density}

Overall, the minimum densities are closely grouped around the average of $1451 \mathrm{~kg} / \mathrm{m}^{3}$. The trial-to-trial standard deviation was about $5 \mathrm{~kg} / \mathrm{m}^{3}$, the operator-to-operator standard deviation was about $12 \mathrm{~kg} / \mathrm{m}^{3}$, and the site-to-site variation was about $8 \mathrm{~kg} /$ $\mathrm{m}^{3}$. The standard deviation for the entire data set (all 90 tests) is $14 \mathrm{~kg} / \mathrm{m}^{3}$ (not provided in Table 2.5). In contrast, a standard deviation of $46 \mathrm{~kg} / \mathrm{m}^{3}$ was provided to the numerical simulation teams by Kutter et al. (2019), which in addition to material variability includes the variability of different procedures to measure density, equipment, and different operators.

Using a two-way analysis of variance framework, the comparison interval, or the vertical length of the standard deviation bar, for each facility can be evaluated to determine if they overlap the mean minimum density of $1451 \mathrm{~kg} / \mathrm{m}^{3}$. The IFSTTAR sample comparison interval does not overlap the mean minimum density line. If the 95\% confidence interval of the mean is considered, which is shown as the gray region surrounding the mean value line, the IFSTTAR comparison interval overlaps with the mean region. The facility-specific minimum densities vary up to $1 \%$ from the mean. The differences appear to be small but statistically distinguishable.

\subsubsection{Discussion of Maximum Density}

Kutter et al. (2019) calculated a standard deviation of $25 \mathrm{~kg} / \mathrm{m}^{3}$ using data aggregated from many laboratories performing different methods to measure maximum density. The standard deviation for the entire data produced for the present paper (all 
30 tests) is only $13 \mathrm{~kg} / \mathrm{m}^{3}$, which is $0.7 \%$ of the maximum density $\left(1753 \mathrm{~kg} / \mathrm{m}^{3}\right)$. This includes trial-to-trial, operator-to-operator, and sample-to-sample variability.

The variability of the STD of the maximum density in Table 2.5 is due to the limited sample size (three samples per STD evaluation). Furthermore, the STD of the maximum density includes trial-to-trial and operator-to-operator variability. For the minimum density test, much of the trial-to-trial variability was removed by averaging the three trials before obtaining $\mathrm{STD}_{\mathrm{O}}$. The STD bars in Fig. 2.3 include operator-to-operator and trial-to-trial variability of all ten maximum density samples which overlap the mean value of the maximum density $1753 \mathrm{~kg} / \mathrm{m}^{3}$. Thus, based on maximum density tests, it is not possible to statistically distinguish soil specimens from each other.

\subsection{Testing Results Effect on Relative Density}

Relative density can be expressed as:

$$
D_{\mathrm{r}}=\frac{\rho_{\max }\left(\rho_{\mathrm{d}}-\rho_{\min }\right)}{\rho_{\mathrm{d}}\left(\rho_{\max }-\rho_{\min }\right)}
$$

where $\rho_{\max }$ is the maximum dry density, $\rho_{\min }$ is the minimum dry density, and $\rho_{\mathrm{d}}$ is the dry density. Equation 2.1 illustrates the sensitivity of relative density to changes in $\rho_{\max }, \rho_{\min }$, and $\rho_{\mathrm{d}}$. For example, if $\rho_{\max }=1752 \mathrm{~kg} / \mathrm{m}^{3}, \rho_{\mathrm{d}}=1600 \mathrm{~kg} / \mathrm{m}^{3}$, and $\rho_{\min }$ is decreased by $1 \%$ from 1486 to $1471 \mathrm{~kg} / \mathrm{m}^{3}$, the calculated relative density would increase $3 \%$ from 47 to $50 \%$; similarly, if $\rho_{\mathrm{d}}$ is increased by $1 \%$ from 1600 to $1616 \mathrm{~kg} / \mathrm{m}^{3}$, the calculated relative density would increase $6 \%$ from 47 to $53 \%$.

Table 2.6 compares relative densities that would be obtained from the reported densities for each LEAP experiment, calculated by mass and volume of sand, using the average index density values determined from the present study $\left(\rho_{\min }=1451 \mathrm{~kg} /\right.$ $\left.\mathrm{m}^{3}, \rho_{\max }=1753 \mathrm{~kg} / \mathrm{m}^{3}\right)$, site-specific average values by the LEAP method $\left(\mathrm{Avg}_{\mathrm{ss}}\right.$ values in Table 2.5), and the average values from the ASTM method $\left(\rho_{\min }=1490.5 \mathrm{~kg} / \mathrm{m}^{3}, \rho_{\max }=1757.0 \mathrm{~kg} / \mathrm{m}^{3}\right)$.

\subsection{Measurements by ASTM Method}

Tabulated in Table 2.7 are index densities using the ASTM procedures 4253 Method $1 \mathrm{~B}$ and 4254 Method A performed by four different professional laboratories and two researchers on three different batches of Ottawa F-65 sand. The results from Cooper Labs (located in Palo Alto, CA) tested material from the March 2013 UC Davis shipment. The material tested was taken from a single bag from the batch. Material sent to Gulf Shores Exploration (located in Rancho Cordova, CA) was 
Table 2.6 Relative densities obtained by using an average, site-specific, and ASTM index density values

\begin{tabular}{|c|c|c|c|c|}
\hline Facility & $\begin{array}{l}\text { Density } \\
\left(\mathrm{kg} / \mathrm{m}^{3}\right)\end{array}$ & $\begin{array}{l}D_{\mathrm{r}}(\%) \\
\left(\rho_{\min }=1451\right. \\
\rho_{\max }=1753 \\
\text { LEAP method } \\
\text { average })\end{array}$ & $\begin{array}{l}D_{\mathrm{r}}(\%)\left(\rho_{\min } \text { and } \rho_{\max }\right. \\
\text { using site-specific, } A v g_{\mathrm{ss}} \text {, } \\
\text { average values from } \\
\text { Table } 2.5)\end{array}$ & $\begin{array}{l}D_{\mathrm{r}}(\%) \\
\left(\rho_{\min }=1490.5\right. \\
\rho_{\max }=1757 \text { ASTM } \\
\text { average from } \\
\text { Table } 2.7)\end{array}$ \\
\hline CU1 & 1656 & $72 \%$ & $71 \%$ & $66 \%$ \\
\hline CU2 & 1606 & $56 \%$ & $55 \%$ & $47 \%$ \\
\hline Ehime1 & 1649 & $70 \%$ & $71 \%$ & $63 \%$ \\
\hline Ehime2 & 1657 & $72 \%$ & $73 \%$ & $66 \%$ \\
\hline Ehime3 & 1693 & $83 \%$ & $84 \%$ & $79 \%$ \\
\hline IFSTTAR1 & 1696 & $84 \%$ & $81 \%$ & $80 \%$ \\
\hline IFSTTAR2 & 1624 & $62 \%$ & $58 \%$ & $54 \%$ \\
\hline KAIST1 & 1701 & $85 \%$ & $87 \%$ & $82 \%$ \\
\hline KAIST2 & 1593 & $52 \%$ & $54 \%$ & $42 \%$ \\
\hline KyU1 & 1683 & $80 \%$ & $82 \%$ & $75 \%$ \\
\hline KyU2 & 1659 & $73 \%$ & $74 \%$ & $67 \%$ \\
\hline KyU3 & 1637 & $66 \%$ & $67 \%$ & $59 \%$ \\
\hline NCU1 & 1652 & $71 \%$ & $72 \%$ & $64 \%$ \\
\hline NCU2 & 1652 & $71 \%$ & $72 \%$ & $64 \%$ \\
\hline NCU3 & 1652 & $71 \%$ & $72 \%$ & $64 \%$ \\
\hline RPI1 & 1650 & $70 \%$ & $71 \%$ & $64 \%$ \\
\hline RPI2 & 1659 & $73 \%$ & $73 \%$ & $67 \%$ \\
\hline RPI3 & 1623 & $62 \%$ & $62 \%$ & $54 \%$ \\
\hline UCD1 & 1665 & $75 \%$ & $75 \%$ & $69 \%$ \\
\hline UCD2 & 1648 & $69 \%$ & $70 \%$ & $63 \%$ \\
\hline UCD3 & 1658 & $72 \%$ & $73 \%$ & $67 \%$ \\
\hline ZJU1 & 1651 & $70 \%$ & $71 \%$ & $64 \%$ \\
\hline ZJU2 & 1599 & $54 \%$ & $55 \%$ & $45 \%$ \\
\hline ZJU3 & 1703 & $86 \%$ & $86 \%$ & $82 \%$ \\
\hline AVG & - & $71 \%$ & $71 \%$ & $65 \%$ \\
\hline
\end{tabular}

mixed from eight different bags, from four different pallets of the March 2013 shipment. The sand was mixed and split into two identical samples without telling the laboratory that the samples were identical. The results from GeoComp Express (NY) used sand from a different shipment. Considering only the four tests done by commercial laboratories (tests 1, 2, 5, and 6), the standard deviations (13.7 and $\left.10.2 \mathrm{~kg} / \mathrm{m}^{3}\right)$ are much less than the standard deviations from all six tests (28.3 and $\left.20.8 \mathrm{~kg} / \mathrm{m}^{3}\right)$. 
Table 2.7 ASTM index dry densities for Ottawa F-65 sand from commercial laboratories and researchers

\begin{tabular}{|c|c|c|c|c|c|}
\hline $\begin{array}{l}\text { Test } \\
\text { no: }\end{array}$ & Testing company & Date & Soil batch & $\begin{array}{l}\text { Minimum } \\
\text { density } \\
(\mathrm{D} 4254 \mathrm{~A}) \\
\left(\mathrm{kg} / \mathrm{m}^{3}\right)\end{array}$ & $\begin{array}{l}\text { Maximum density } \\
\text { (D4253-1B) } \\
\left(\mathrm{kg} / \mathrm{m}^{3}\right)\end{array}$ \\
\hline 1 & Cooper Labs & $\begin{array}{l}\text { Apr } \\
13\end{array}$ & $\begin{array}{l}\text { UC Davis } \\
\text { March } \\
2013\end{array}$ & 1515 & 1736 \\
\hline 2 & GeoComp Express & $\begin{array}{l}\text { Dec } \\
14\end{array}$ & $\begin{array}{l}\text { RPI } \\
\text { shipment }\end{array}$ & 1494 & 1758 \\
\hline 3 & Vasko (2015) & $\begin{array}{l}\text { Dec } \\
14\end{array}$ & $\begin{array}{l}\text { GWU } \\
\text { shipment }\end{array}$ & 1538 & 1793 \\
\hline 4 & Parra Bastidas (2016) & $\begin{array}{l}\text { Jun } \\
15\end{array}$ & $\begin{array}{l}\text { UC Davis } \\
\text { March } \\
2013\end{array}$ & 1455 & Not measured \\
\hline 5 & $\begin{array}{l}\text { Gulf Shore Exploration } \\
\text { and Testing (test } 1 \text { of 2) }\end{array}$ & $\begin{array}{l}\text { May } \\
18\end{array}$ & $\begin{array}{l}\text { UC Davis } \\
\text { March } \\
2013\end{array}$ & 1485 & 1752 \\
\hline 6 & $\begin{array}{l}\text { Gulf Shore Exploration } \\
\text { and Testing (test } 2 \text { of 2) }\end{array}$ & $\begin{array}{l}\text { May } \\
18\end{array}$ & $\begin{array}{l}\text { UC Davis } \\
\text { March } \\
2013\end{array}$ & 1487 & 1757 \\
\hline & \multicolumn{3}{|l|}{ Average (tests $1,2,5,6$ ) } & 1485.0 & 1744.0 \\
\hline & \multicolumn{3}{|l|}{ Median (tests $1,2,5,6$ ) } & 1490.5 & 1754.5 \\
\hline & \multicolumn{3}{|l|}{ STD (tests $1,2,5,6$ ) } & 13.7 & 10.2 \\
\hline & \multicolumn{3}{|l|}{ Average (tests 1-6) } & 1495.7 & 1759.2 \\
\hline & \multicolumn{3}{|l|}{ STD (tests 1-6) } & 28.3 & 20.8 \\
\hline & \multicolumn{3}{|l|}{ Median (tests 1-6) } & 1490.5 & 1757.0 \\
\hline
\end{tabular}

\subsection{Conclusions}

Ottawa F-65, an unprocessed mined sand, was chosen as the standard sand for LEAP-UCD-2017. Most of the LEAP-UCD-2017 experiments were performed with sand shipped from one large shipment to UCD in March 2013. GWU and RPI ordered sand independently from different shipments. Between December 2017 and February 2018, the nine centrifuge facilities participating in LEAP-UCD-2017 and GWU sent $500 \mathrm{~g}$ samples of their Ottawa F-65 sand to UC Davis for quality control testing. Index dry densities using the LEAP method and grain size analysis were performed to determine how consistent the sand was across the facilities.

The sand used for the LEAP-UCD-2017 exercise at different facilities was reasonably consistent, but it does seem from this suite of testing that there are small but detectable differences in the index dry densities; the differences might 
affect the computed relative densities by up to $4 \%$. However, the measured site-tosite variability is less than the operator-to-operator variability. The LEAP procedure to measure index dry densities produces consistent results, lending credence to the procedure's use as a quality control measure. The LEAP procedures give median values $\rho_{\min }=1451 \mathrm{~kg} / \mathrm{m}^{3}, \rho_{\max }=1753 \mathrm{~kg} / \mathrm{m}^{3}$.

The ASTM procedures, including several tests by commercial laboratories, produced different values. The relative densities using ASTM procedures are 4-10\% smaller than the relative densities that would be calculated using the LEAP procedures. It is believed that ASTM procedures are more likely to be representative of procedures used in liquefaction literature. We therefore recommend using the median ASTM values for future analysis of LEAP data: $\rho_{\min }=1490.5 \mathrm{~kg} / \mathrm{m}^{3}$, $\rho_{\max }=1757.0 \mathrm{~kg} / \mathrm{m}^{3}$.

Acknowledgments This study was supported by NSF CMMI Grant Number 1635307. The authors appreciate the assistance of the researchers at all of the LEAP-UCD-2017 experiment sites for providing their grain size analysis, index density tests, and for sending the required samples back to UC Davis.

\section{References}

El Ghoraiby, M. A., Park, H., Manzari, M. T. (2017). LEAP2017: Soil characterization and element tests for Ottawa F65 Sand. Report by George Washington University, Washington, DC, 14th March 2017, 37p.

Kutter, B. L., Carey, T. J., Bonab, M. H., Stone, N., Manzari M., Zeghal M., Escoffier, S., Haigh, S., Madabhushi, G., Hung, W., Kim, D., Kim, N., Okamura, M., Tobita, T., Ueda, K., Zhou, Y. (2019). LEAP UCD 2017. 1.01 model specifications. In B. Kutter et al. (Eds.), Model tests and numerical simulations of liquefaction and lateral spreading: LEAP-UCD-2017. New York: Springer.

Kutter, B. L., Carey, T. J., Hashimoto, T., Zeghal, M., Abdoun, T., Kokkali, P., Madabhushi, G., Haigh, S. K., Burali d'Arezzo, F., Madabhushi, S., Hung, W.-Y., Lee, C.-J., Cheng, H.-C., Iai, S., Tobita, T., Ashino, T., Ren, J., Zhou, Y.-G., Chen, Y.-M., Sun, Z.-B., \& Manzari, M. T. (2017). LEAP-GWU-2015 experiment specifications, results, and comparisons. Soil Dynamics and Earthquake Engineering, 113, 616-628. https://doi.org/10.1016/j.soildyn.2017.05.018.

Lade, P. V. (1988). Double hardening constitutive model for soils, parameter determination and predictions for two sands. Constitutive Equations for Granular Non-Cohesive Soils, 367-382.

Parra Bastidas, A. M. (2016). Ottawa F-65 Sand Characterization. PhD Dissertation, University of California, Davis.

Tiedemann, D. A. (1973). Variability of laboratory relative density test results. In Evaluation of relative density and its role in geotechnical projects involving Cohesionless soils. ASTM International.

Vasko, A. (2015). An investigation into the behavior of Ottawa sand through monotonic and cyclic shear tests. MS Thesis, George Washington University.

Ziotopoulou, K., Montgomery, J., Parra Bastidas, A. M., Morales, B. (2018). Cyclic Strength of Ottawa F-65 Sand: Laboratory Testing and Constitutive Model Calibration: Geotechnical Earthquake Engineering and Soil Dynamics V. The University of Texas at Austin, 10-13 June 2018. 
Open Access This chapter is licensed under the terms of the Creative Commons Attribution 4.0 International Licence (http://creativecommons.org/licenses/by/4.0/), which permits use, sharing, adaptation, distribution and reproduction in any medium or format, as long as you give appropriate credit to the original author(s) and the source, provide a link to the Creative Commons licence and indicate if changes were made.

The images or other third party material in this chapter are included in the chapter's Creative Commons licence, unless indicated otherwise in a credit line to the material. If material is not included in the chapter's Creative Commons licence and your intended use is not permitted by statutory regulation or exceeds the permitted use, you will need to obtain permission directly from the copyright holder. 